\title{
Sistem Pemarkahan Oblik dalam Buku Minna no Nihongo Chuukyuu
}

\author{
Ni Luh Desy Purnama Dewi ${ }^{1)}$, Ni Putu Luhur Wedayanti ${ }^{2)}$ \\ Program Studi Sastra Jepang, Fakultas Ilmu Budaya, Universitas Udayana \\ Denpasar, Bali-Indonesia \\ [nidesydewi@gmail.com],[luhur_wedayanti@unud.ac.id]
}

\begin{abstract}
Abstrak
Penelitian ini berjudul Sistem Pemarkahan Oblik dalam Buku Minna no Nihongo Сhиикуии. Tujuan penelitian ini adalah untuk menganalisis sistem pemarkah oblik dalam buku Minna no Nihongo Chuukyuu. Metode penelitian yang digunakan dalam penelitian ini adalah metode deskriptif kualitatif. Sumber data yang digunakan dalam penelitian ini adalah buku Minna no Nihongo Chuukyuu I \& II.

Hasil penelitian yang didapat, terdapat tujuh jenis oblik bahasa Jepang dalam buku Minna no Nihongo Chuиkyu dan memiliki pemarkah yang berbeda. Oblik tersebut adalah oblik lokasi, komitatif, sasaran, instrumen, sumber, agen dan penerima. Terdapat pula posposisi $n i, d e, t o, e$, kara, dan made sebagai pemarkah oblik.
\end{abstract}

Kata kunci: oblik, posposisi, partikel

\begin{abstract}
The title of this research is "Oblique Marking System in Minna no Nihongo Chuukyuu's Book". The purpose of this study is to analyze the oblique marking system in the book Minna no Nihongo Chuukyuu. The methods and techniques used in this study are the methods and techniques for the direct elements.

The research results obtained, there are seven types of Japanese oblique in the book Minna no Nihongo Chuukyuu and have different markers. The types of oblique are location oblique, comitative, target oblique, instrument oblique, source oblique, agent oblique and recipient oblique. In addition to oblique types, there are also pospositions ni, de, to, e, kara, and made as oblique markers.
\end{abstract}

Keywords: oblique, posposition, particle

\section{Pendahuluan}

Pembelajaran bahasa asing yaitu bahasa Jepang di Indonesia, khususnya di Bali semakin berkembang. Namun, karakteristik bahasa Jepang yang berbeda dengan bahasa Indonesia membuat para pembelajar bahasa Jepang mengalami kesulitan. Selain memiliki pola urutan kalimat yang berbeda dengan bahasa Indonesia, bahasa Jepang juga memiliki keunikan tersendiri karena hampir setiap fungsi gramatikal dalam kalimatnya selalu dimarkahi oleh partikel (joshi). Dalam bahasa Jepang partikel terletak setelah nomina yang diterangkan. Kemunculan partikel sangat membantu untuk 
mengetahui makna sebuah kalimat bahasa Jepang, tetapi seringkali partikel tersebut yang membingungkan para pembelajar bahasa Jepang.

Partikel dalam bahasa Jepang dapat dibedakan menjadi beberapa jenis berdasarkan fungsinya dalam kalimat, seperti misalnya dalam kalimat yang menunjukkan oblik. Partikel yang memarkahi oblik disebut dengan posposisi. Partikel yang berfungsi sebagai pemarkah unsur dalam kalimat disebut kakujoshi atau partikel kasus. Berkaitan dengan hal tersebut, maka dalam penelitian ini dipaparkan lebih rinci mengenai kakujoshi atau partikel kasus, serta oblik.

Terdapat lima partikel kasus dalam bahasa Jepang, yaitu partikel ga (nomina) menyatakan subjek klausa. Partikel $o$ (akusatif) menyatakan objek langsung. Partikel $n i$ (datif) menyatakan penerima. Partikel no (genetif) menyatakan hubungan kepemilikan. Partikel wa berfungsi hanya sebagai penanda topik. Tiap-tiap partikel kasus memiliki hubungan dan fungsi gramatikal dalam kalimat. (Tsujimura, 1997-134). Partikel kasus dalam bahasa Jepang yang memiliki kaitan erat dalam pembentukan oblik adalah partikel $n i$, de, e, to, kara, dan made. Penjelasan mengenai partikel tersebut adalah menurut Maynard (1995:59-61).

Partikel dalam bahasa Jepang tidak selalu memarkahi sebuah fungsi gramatikal yang sama. Begitu pula halnya dengan sebuah fungsi gramatikal. Fungsi gramatikal yang sama tidak selalu dimarkahi oleh partikel yang sama. Namun, terdapat pola yang dapat menentukan pemarkahan dalam suatu kalimat. Penelitian ini mengulas tentang pemarkahan fungsi gramatikal, yaitu oblik dalam bacaan bahasa Jepang yang terdapat pada buku Minna no Nihongo Chuиkyuи I \& II.

Penelitian ini memiliki dua tujuan yaitu tujuan secara umum dan tujuan secara khusus. Secara umum penelitian ini diharapkan dapat memberikan pemahaman mengenai oblik bahasa Jepang. Selain itu, juga dapat dijadikan pembelajaran dan perbandingan bagi pemelajar bahasa Jepang untuk penelitian pada aspek lain yang memiliki keterkaitan dengan penelitian ini. Tujuan khusus penelitian ini adalah untuk mengetahui struktur klausa yang mengandung oblik dalam buku Minna no Nihongo Chuиkуuи I\& II. 


\section{Metode dan Teori}

\subsection{Metode Penelitian}

Objek kajian penelitian ini berupa buku pelajaran bahasa Jepang yang dipergunakan oleh mahasiswa strata satu di Universitas Udayana, yaitu buku Minna no Nihongo Chuиkyuu I dan II terbitan 3A Corporation. Data oblik diambil dari bacaan yang terdapat dalam buku tersebut. Judul dari bacaan tersebut antara lain yang terdapat pada buku Minna no Nihongo Chuиkyuи I (Yamadasan taku de, Gaikokugo, Kaigai de Nihon no Terebi Anime ga Ukeru Wake, Koohii Syoppu de, Animeesyon), kemudian yang terdapat pada buku Minna no Nihongo Chuukyuu II (Hataraki Ari, Torihiki no Paatii de, Tatami, Gairaigo, dan Denwa Girai). Data oblik diambil dari beberapa bacaan yang terdapat dalam buku Minna no Nihongo Chuukyuu I \& II karena data oblik yang ada pada bacaan tersebut mewakili keseluruhan data oblik yang terdapat dalam buku.

Data yang terkumpul diklasifikasi berdasarkan jenis oblik yang ditunjukkan. Kemudian oblik dianalisis secara deskriptif dengan menggunakan metode agih dan teknik bagi unsur langsung (Sudaryanto, 2015). Metode yang dipergunakan dalam penyajian hasil dan analisis data pada penelitian ini adalah metode formal dan informal.

\subsection{Teori}

Penelitian ini menggunakan beberapa teori, yaitu teori sintaksis yang dikemukakan oleh Nitta (1997), teori partikel yang dikemukakan oleh Maynard (1995), teori posposisi oleh Tsujimura 1997, Tsujimura (2014) dan teori fungsi gramatikal oleh Kroeger (2005), serta definisi oblik menurut Kroeger (2005) dan Blake (1994).

\section{Kajian Pustaka}

Penelitian sebelumnya relevan terhadap tulisan ini karena secara umum membahas mengenai oblik dan penulis mendapatkan informasi yang cukup dari penelitian sebelumnya. Beberapa penelitian sebelumnya yang masih relevan digunakan dalam penelitian ini sebagai referensi yaitu Purnawati (2010, 2012, 2019), Wiriani (2016), dan Novianti (2016). 
Purnawati (2010) dalam penelitiannya yang berjudul "Pemarkahan Fungsi Gramatikal Oblik Lokasi, Asal, dan Tujuan dalam Bahasa Indonesia dan Bahasa Jepang", Purnawati (2012) dalam penelitiannya yang berjudul "Interaksi Oblik dengan Topik dalam Bahasa Jepang”, Purnawati dkk (2019) dalam penelitiannya yang berjudul "Pemarkah Fungsi Gramatikal Oblik Lokasi, Asal dan Tujuan dalam Bahasa Indonesia dan Bahasa Jepang". Wiriani (2016) dalam penelitiannya yang berjudul "Sistem Pemarkah Oblik dalam Klausa Bahasa Jepang” menganalisis tentang pemarkah oblik dalam klausa Bahasa Jepang. Novianti (2016) dalam penelitiannya yang berjudul "Analisis Kesalahan Penggunaan Partikel de, ni, dan o Pada Kalimat Pembelajar Bahasa Jepang" mengulas tentang kesalahan penggunaan partikel sebagai posposisi yang memiliki berbagai macam peran.

\section{Hasil dan Pembahasan}

\subsection{Sistem Pemarkah Oblik dalam Buku Minna no Nihongo Chuukyuu}

Menurut Kroeger, (2004:15) dalam satu kalimat dapat muncul dua oblik secara bersamaan. Namun, oblik yang dimarkahi oleh posposisi yang memiliki peran semantis yang sama, tidak dapat muncul secara bersamaan.

Pada buku Minna no Nihongo Chukyuu I dan II ditemukan tujuh jenis oblik, yaitu oblik lokasi, komitatif, sasaran, instrumen, sumber, agen dan penerima. Adapun oblik yang terdapat dalam buku tersebut memiliki pemarkah yang sama, tetapi memiliki makna yang berbeda akibat perbedaan verba yang dipergunakan dalam kalimat bersangkutan.

Sistem pemarkah oblik dalam buku Minna no Nihongo Chuukyuu dapat dilihat pada tabel berikut.

Tabel Sistem Pemarkah Oblik dalam Buku Minna no Nihongo Chuukyuu

\begin{tabular}{|c|l|r|r|r|r|r|c|}
\hline \multirow{2}{*}{ No } & \multirow{2}{*}{ Jenis Oblik } & \multicolumn{7}{|c|}{ Partikel } \\
\cline { 3 - 8 } & & $e$ & $d e$ & $n i$ & kara & made & to \\
\hline 1 & Oblik lokasi & & 0 & $\circ$ & & & \\
\hline 2 & Oblik instrumen & & 0 & & & & \\
\hline 3 & Oblik komitatif & & & & & & 0 \\
\hline 4 & Oblik sasaran & $\circ$ & & 0 & & 0 & \\
\hline 5 & Oblik sumber & & & & $\circ$ & & \\
\hline 6 & Oblik agen & & & $\circ$ & $\circ$ & & \\
\hline
\end{tabular}




\section{\begin{tabular}{|l|l|l|l|l|l|l|l|}
\hline 7 & Oblik penerima & & & 0 & & & \\
\hline
\end{tabular}}

Oblik lokasi dalam bahasa Jepang dapat dimarkahi oleh posposisi $n i$ atau $d e$. Partikel $n i$ dipergunakan untuk menunjukkan arah dan lokasi tempat terjadinya sesuatu, sedangkan partikel de dipergunakan untuk menunjukkan suatu kegiatan di suatu tempat. Penggunaan partikel $n i$ dapat dilihat pada contoh kalimat di bawah ini.

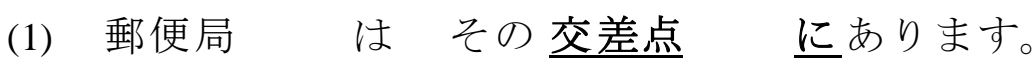

Yuubinkyoku wa sono kousaten ni arimasu.

Kantor pos TOP itu persimpangandi ada

'Kantor pos ada di persimpangan itu'

(Minna no Nihongo Chuukyuu I, 2008:31

(2) 大阪

Oosaka $\quad \underline{\boldsymbol{n i}}$ sunde inagara mada

Oosaka di selamatinggal belum

食べたことが ないんです。

tabeta koto ga naindesu.

makan NOMtidak

'Saya tinggal di Osaka tetapi belum pernah memakannya'

(Minna no Nihongo Chuukyuu II, 2012:6)

Contoh (1) dan (2) merupakan oblik lokasi yang dimarkahi oleh posposisi ni. Pada contoh (1) oblik diisi oleh frasa nomina kousaten 'persimpangan'. Verba yang digunakan adalah arimasu 'ada'. Kemudian pada contoh (2) diisi oleh frasa Oosaka 'Osaka'. Verba yang digunakan adalah verba sumu 'tinggal'. Pemarkah $n i$ 'di' digunakan sebab partikel $n i$ berfungsi untuk menunjukkan lokasi tanpa adanya aktivitas tertentu.

Apabila lokasi yang ditunjukkan merupakan lokasi terjadinya suatu aktivitas, maka oblik lokasi dimarkahi oleh partikel de. Penggunaannya dapat dilihat pada contoh kalimat berikut ini.

(3) 現在日本製のアニメ は 世界中

Genzai nipponseino anime wa sekaijuu

Saat ini anime buatan Jepang TOP seluruh dunia

で テレビ 放映されている。

$\underline{\underline{d e}}$ terebi houeisareteiru.

di televisi ditayangkan

'Saat ini, anime buatan Jepang ditayangkan oleh televisi di seluruh dunia'

(Minna no Nihongo Chuukyuu II, 2012:14) 
(4) 弟の次郎君校ななしくて あまり

Otouto no Jiro kun wa otonashikute amari

Saudara saya Jiro TOP pendiam dan tidak terlalu

外军遊ばない。

soto $\overline{\mathrm{de}}$ asobanai.

luar di tidak bermain

'Adik laki-laki saya bernama Jiro, pendiam dan tidak banyak bermain di luar' (Minna no Nihongo Chuukyuu I, 2008:141)

Oblik lokasi contoh (3) dan (4) dimarkahi oleh posposisi de 'di'. Pada contoh (3) terdapat frasa nomina sekai juu 'seluruh dunia'. Verba yang digunakan adalah houeisareteiru 'ditayangkan'. Kemudian pada contoh (4) terdapat frasa nomina soto 'luar'. Verba yang digunakan adalah asobanai 'bermain'. Pemarkah yang digunakan adalah posposisi de 'di' sebab kalimat tersebut menunjukkan bahwa ada sesuatu kegiatan yang dilakukan pada lokasi yang ditunjukkan oleh posposisi $d e$.

Perbedaan penggunaan posposisi $n i$ dan de pada suatu oblik lokasi secara garis besar terletak pada verba. Apabila digunakan posposisi $n i$, maka partikel yang memarkahi oblik yaitu $n i$ menjelaskan lokasi tanpa adanya aktivitas tertentu. Namun, jika partikel yang digunakan adalah de, maka pemarkah tersebut menjelaskan pada sebuah lokasi terdapat suatu aktivitas.

Selain itu, terdapat pula posposisi $n i$ dan de muncul dalam satu kalimat. Perhatikan contoh di bawah ini.

（5）箱根 で どこ に 泊まりますか。

$\underline{\text { Hakone }} \overline{\text { de }} \overline{\text { doko }} \quad \underline{\text { ni }}$ tomarimasuka.

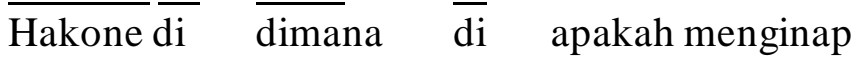

'Di Kota Hakone dimana menginap?'

(Minna no Nihongo Chuukyuu II, 2012:75)

Pada contoh (5) terdapat klausa yang memiliki dua oblik. Fungsi oblik yang muncul adalah oblik lokasi. Terdapat frasa nomina hakone 'Kota Hakone' yang dimarkahi oleh posposisi $d e$. Kemudian terdapat frasa nomina doko 'dimana' yang dimarkahi oleh posposisi ni. Verba yang digunakan pada contoh (5) adalah tomarimasuka 'apakah menginap?'.

Selain sebagai pemarkah oblik lokasi, posposisi de juga dapat dipergunakan sebagai pemarkah oblik instrumen. 
Menurut Iori (2014:17) posposisi dalam bahasa Jepang bisa memiliki makna yang berbeda pada kalimat yang berbeda berdasarkan frasa nomina yang muncul di depannya. Misalnya, seperti de ningyou o tsukutta 'membuat boneka'. Dijelaskan bahwa jika di depan partikel diisi oleh frasa nomina kyoushitsu 'kelas', maka partikel de berfungsi untuk menunjukkan lokasi. Namun, jika di depan partikel de diisi frasa nomina kami 'kertas', maka partikel de tersebut berfungsi untuk menunjukkan bahan baku. berikut.

Pada penelitian ini ditemukan oblik instrumen, adapun contohnya adalah sebagai

(6)

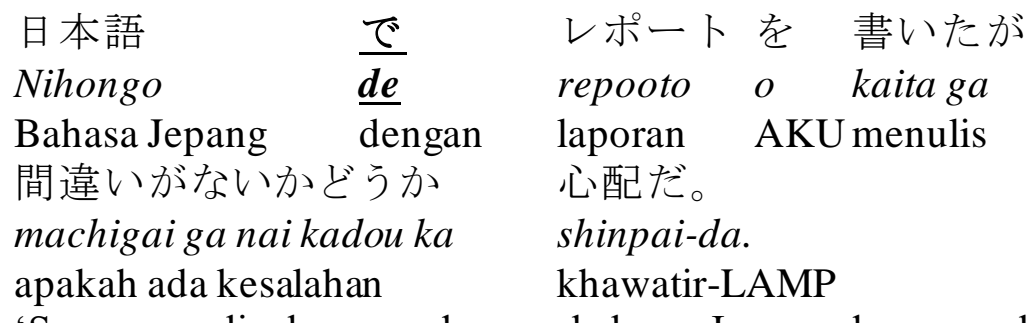

'Saya menulis laporan dengan bahasa Jepang dan saya khawatir jika saya melakukan kesalahan'

(Minna no Nihongo Chuukyuu I, 2008:2)

(7) その 伝統的な 方法至をたてて飲む人 Sono dentoutekina houhou $\overline{\mathrm{de}} \quad$ ochaotatetenomu hito Itu tradisional cara dengan seseorangmembuat teh は非常に 少なく なっています。 wa hijouni sukunaku natteimasu. TOP sangat sedikit menjadi 'Sangat sedikit orang yang membuat dan minum teh dengan metode tradisional' (Minna no Nihongo Chuukyuu I, 2008:15)

(8) かたかな

Katakana Huruf katakana 分からなくて wakaranakute mengerti-tidak 'Pernahkah anda mengalami kesulitan dalam memahami kata-kata bahasa Jepang yang ditulis dengan huruf katakana?'

(Minna no Nihongo Chuukyuu I, 2008:25)

Oblik instrumen pada contoh (6), (7) dan (8) masing-masing ditunjukkan oleh nomina nihongo 'bahasa Jepang', frasa nomina sono dentoutekina houhou 'metode tradisional itu', dan nomina katakana 'huruf katakana'. Ketiga oblik instrumen tersebut 
diikuti posposisi de 'dengan'. Sebab frasa nomina yang ada di depan partikel de tidak mengacu pada lokasi, melainkan nomina.

Oblik komitatif dalam bahasa Jepang dimarkahi oleh posposisi to. Partikel to dipergunakan untuk menandai suatu aksi yang berlangsung secara bersamaan (join action or with) dan dipergunakan untuk memarkahi enumerative atau batasan suatu istilah. Contoh penggunaannya dapat dilihat pada kalimat di bawah ini.

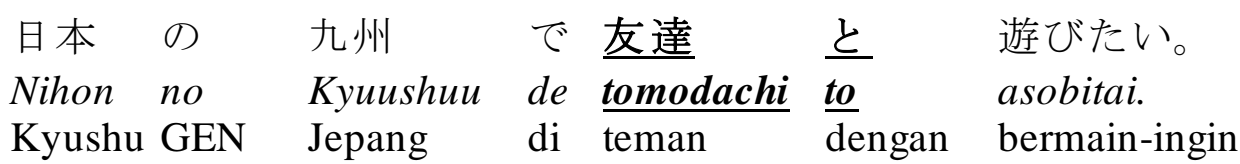

'Saya ingin bermain dengan teman di Kyushu Jepang' (Minna no Nihongo Chuukyuu I, 2008:46)

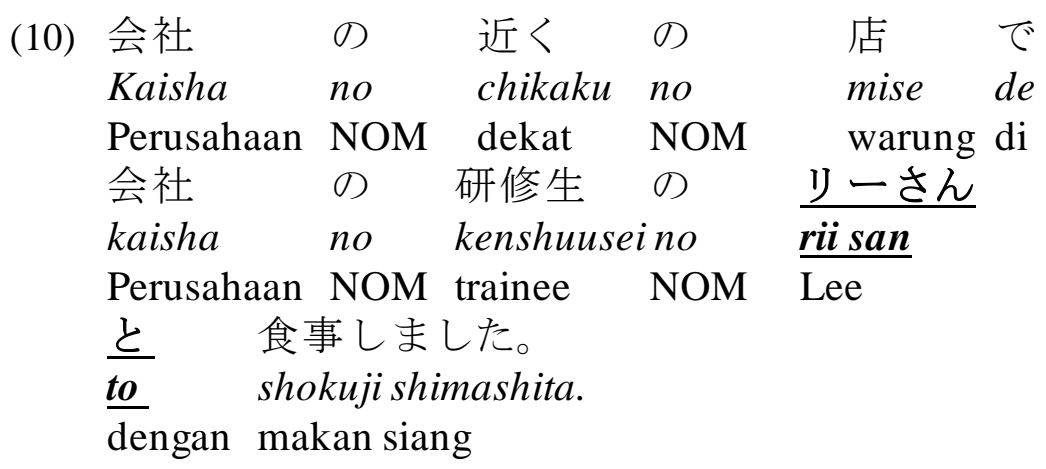

'Saya makan bersama dengan trainee perusahaan bernama Lee di sebuah warung dekat perusahaan'

(Minna no Nihongo Chuukyuu I, 2008:155)

Oblik komitatif pada contoh (9) dan (10) masing-masing ditunjukkan oleh nomina koohii 'kopi', frasa nomina Igirisu no shoujo 'gadis inggris'. Kedua oblik komitatif di atas dimarkahi dengan posposisi to 'dan'.

Oblik sasaran dalam buku Minna no Nihongo dimarkahi oleh posposisi $e$, ni dan made. Maynard, (1995:59-61) mengemukakan bahwa partikel $e$ dipergunakan untuk menyatakan oblik sasaran yang berupa tempat, partikel ni dipergunakan untuk menyatakan oblik sasaran yang berupa kegiatan dan partikel made dipergunakan untuk menunjukkan titik akhir terjadinya sesuatu (sampai, hingga). Contoh penggunaannya dapat dilihat pada kalimat di bawah ini.
(11) 僕
Boku
はアメリカから日本
乞 来て、
wa Amerika kara Nihon
$\underline{\boldsymbol{e}} \quad$ kite,
Saya
TOP Amerika
dari Jepang
ke datang 


\section{もう 5 年 になる。 \\ mou 5 nen ninaru. \\ sudah 5 tahun menjadi}

'Sudah 5 tahun sejak saya datang ke Jepang dari Amerika'

(Minna no Nihongo Chuukyuu I, 2008:26)

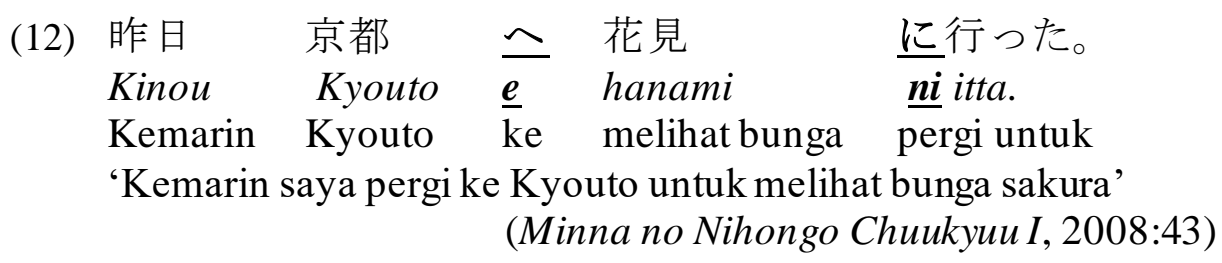

Contoh (11) menunjukkan bahwa posisi $e$ dipergunakan untuk memarkahi oblik sasaran yang menunjukkan tempat, yaitu nihon 'Jepang'. Pada kalimat (12) oblik sasaran diisi oleh frasa nomina kinou kyouto 'kyouto kemarin' yang dimarkahi oleh posposisi $e$ 'ke', selain itu terdapat pula posposisi $n i$ 'untuk' yang digunakan untuk memarkahi nomina hanami 'melihat bunga'. Dari contoh kalimat di atas, dapat dinyatakan bahwa posposisi $e$ dipergunakan untuk memarkahi oblik sasaran yang berupa tempat, sedangkan posposisi $n i$ digunakan untuk memarkahi oblik sasaran yang bukan merupakan tempat, melainkan menerangkan kegiatan. Contoh kalimat lain yang juga menunjukkan oblik sasaran yang dimarkahi dengan posposisi $n i$ dan $e$ dapat dilihat pada kalimat berikut.

(13) うち へ帰ってきたらこんなもの が

Uchi $\underline{\boldsymbol{e}}$ kaettekitara konnamono ga

Rumah ke ketika kembali hal seperti NOM

入っていたんですが。

haitte itan desuga.

berada di KOP

'Ketika saya kembali ke rumah saya menemukan sesuatu seperti ini'

(Minna no Nihongo Chuukyuu I, 2008:22)

(14) 今晚仕事䒹終わつたら

Konban shigoto ga owattara

Kerja malam NOM selesai

飲多比きましょう。

nomi $\underline{n i}$ ikimashou.

Minum untuk pergi-ayo

'Setelah bekerja malam ini, ayo pergi untuk minum'

(Minna no Nihongo Chuukyuu I, 2008:28) 
(15) 空港まで だれが IMC の 社長

Kunkou made dare ga IMC no shachou

Sampai bandara siapa GEN IMC NOMI Kepala perusahaan

を迎え行くんですか。

o mukae $\overline{\text { ni }}$ ikun desuka.

AKU jemput untuk pergi-TNY

'Siapa yang akan pergi untuk menjemput kepala IMC di bandara?

(Minna no Nihongo Chuиkyuu I, 2008:32)

Oblik sasaran pada contoh (13) diisi oleh nomina uchi 'rumah' dan diikuti oleh pemarkah $e$ 'ke'. Posposisi $e$ dipergunakan karena oblik dalam kalimat (13) menunjukkan suatu tempat. Berbeda halnya dengan contoh (14), terdapat nomina nomi 'minum' dan pada contoh (15), terdapat nomina mukae 'jemput' yang dimarkahi oleh posposisi $n i$ 'untuk' karena nomina tersebut menunjukkan suatu kegiatan. Selain posposisi $n i$ dan $e$, ditemukan pula posposisi made yang dipergunakan untuk menunjukkan titik akhir terjadinya sesuatu. Contoh oblik sasaran yang dimarkahi posposisi made adalah sebagai berikut.

(16) その場所まで 連れて行って あげたって言うんですよ。

Sono bashomade tsurete itte agetatte iundesuyo.

Tempat itu sampai membawa mengatakan memberinya

'Dia mengatakan bahwa dia membawanya sampai ke tempat itu'

(Minna no Nihongo Chuukyuu II, 2012:6)

Oblik sasaran pada contoh (16) diisi oleh frasa nomina sono basho 'tempat itu' yang diikuti oleh posposisi made 'sampai'. Penggunaan partikel made dalam bahasa Jepang sangat luas, tetapi dalam data yang ditemukan, oblik sasaran yang menggunakan posposisi made merupakan kalimat yang menunjukkan suatu tempat yang menjadi titik akhir terjadinya suatu kegiatan.

Oblik sumber dalam bahasa Jepang dimarkahi oleh posposisi kara. Oblik tersebut dikatakan sebagai oblik sumber karena biasanya partikel kara dipergunakan untuk menunjukkan titik awal terjadinya sesuatu, Maynard, (1995:59-61). Contoh penggunaannya dapat dilihat pada kalimat di bawah ini.

$\begin{array}{lll}\text { やまと言葉 } & \text { の たたむ } & \text { から重ねる } \\ \text { Yamato kotoba } & \text { no tatamu } & \underline{\text { kara }} \text { kasaneru } \\ \text { Kata Yamato } & \text { GEN tatamu } & \text { dari tumpuk }\end{array}$




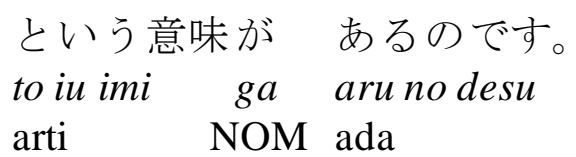

'Ada arti 'menumpuk' yang berasal dari bahasa Yamato tatamu'

(Minna no Nihongo Chuukyuu I, 2008:12)

(18) 合掌造り は 白川郷綮しい自然条件

Gasshou tsukuri wa shirakawa gou no kibishii shizen jouken

Rumah jerami TOP Shirakawa GEN kondisi alam yang keras

から 生まれたものだったのだ。

kara umareta mono datta noda.

dari itu lahir (LAMP)

'Rumah jerami terlahir dari kondisi alam yang keras di Shirakawa'

(Minna no Nihongo Chuиkyuu I, 2008:152)

Pada contoh (17) dan (18) terdapat oblik sumber yaitu tatamu 'tumpuk' dan kibishii shizen jouken 'kondisi alam yang keras' diikuti oleh posposisi kara 'dari'. Kedua contoh tersebut menunjukkan titik awal terjadinya sesuatu seperti yang ditunjukkan pada contoh di atas.

Oblik agen dalam bahasa Jepang dimarkahi oleh posposisi ni. Pada data ditemukan penggunaan oblik agen pada konstruksi pasif bahasa Jepang. Pemarkahan oblik agen dapat dilihat pada contoh di bawah ini.

(19) 私

は 先生に叱られてました。

Watashi wa sensei $\underline{\text { ni }}$ shikararetemashita.

Saya TOP guru oleh marah-PAS

'Saya dimarahi oleh guru'

(Minna no Nihongo Chuukyuu I, 2008:149)

Pada contoh (19) terdapat oblik agen yang ditunjukkan oleh nomina sensei 'guru' dan diikuti oleh posposisi $n i$ kemudian diikuti oleh verba bentuk $\sim t e+$ verba bentuk $\sim$ ta.

Selain untuk memarkahi oblik agen, posposisi $n i$ 'kepada' bergantung verba yang digunakan dalam kalimat. Contoh oblik penerima yang dimarkahi oleh posposisi $n i$ 'kepada' dapat dilihat pada kalimat berikut.

$\begin{array}{llll}\text { (20) お子さんの特徵 } & \text { は? } & \text { 私たち } & \text { に 来ているもの } \\ \text { Okosan no tokuchou } & \text { wa? } & \text { Watashitachi } & \underline{\underline{\boldsymbol{n i}}} \text { kite iru mono } \\ \text { Karakteristik anak } & \text { TOP } & \text { kami } & \text { kepada hal yang terjadi } \\ \text { を } & \text { 教えて } & \text { 下さい。 } & \\ o \quad \text { oshiete } & \text { kudasai. } & & \\ \text { AKU } & \text { beri tahu } & \text { tolong } & \end{array}$


'Bagaimanakah karakteristik anak anda? Tolong beri tahu kami apa yang terjadi' (Minna no Nihongo Chuиkyuu I, 2008:107)

Selain memarkahi oblik agen, posposisi $n i$ 'kepada' dikatakan memarkahi oblik penerima bergantung pada verba yang digunakan dalam kalimat. Contoh tersebut terdapat pada kalimat (20), pada kalimat tersebut terdapat nomina watashitachi 'kami' yang diikuti oleh posposisi $n i$, kemudian terdapat pula verba oshiete kudasai 'tolong beri tahu' yang memperlihatkan bahwa watashitachi 'kami' yang menerima suatu informasi.

\section{Simpulan}

Berdasarkan analisis yang telah dilakukan, maka dapat disimpulkan bahwa terdapat 20 data oblik yang muncul pada beberapa bagian essay atau bacaan dalam buku Minna no Nihongo Chuиkyuu I \& II. Dalam bahasa Jepang oblik termasuk ke dalam argumen noninti. Selain itu dalam bahasa Jepang dikenal dengan istilah posposisi yang dipergunakan untuk memarkahi suatu frasa oblik. Posposisi muncul setelah frasa dan posposisi menjelaskan frasa yang ada di depannya. Dalam essay atau bacaan yang terdapat pada buku Minna no Nihongo Chииkyиu I \& II ditemukan tujuh jenis oblik yang memiliki pemarkah yang berbeda. Oblik tersebut yaitu oblik lokasi yang dimarkahi oleh posposisi $n i$ dan de, oblik instrumen yang dimarkahi oleh posposisi $d e$, oblik komitatif yang dimarkahi oleh posposisi to, oblik sasaran yang dimarkahi oleh posposisi $n i$, e, made, oblik sumber yang dimarkahi oleh posposisi kara, oblik agen yang dimarkahi oleh posposisi $n i$, dan oblik penerima yang dimarkahi oleh posposisi $n i$ pula.

\section{Daftar Pustaka}

Isao, Iori. 2000. Nihongo Bunpou Handobuku. Tokyo: 3 A Corporation.

Kroeger, Paul R. 2004. Analyzing Syntax A Lexical-functional Approach. Cambridge: Cambridge University Press.

Kroeger, Paul R. 2005. Analyzing Grammar an Introduction. Cambridge: Cambridge University Press. 
Maynard, Senko K. 1995. An Introduction to Japanese Grammar and Communication Strategies. Tokyo: The Japan Times.

Sudaryanto. 2015. Metode dan Aneka Teknik Analisis Bahasa. Yogyakarta: Duta Wacana University Press.

Takuji, Kobayashi. 2008. Minna no Nihongo Chuukyuu Ichi Hon Saku. Tokyo: 3A Corporation.

Takuji, Kobayashi. 2012. Minna no Nihongo Chuukyuu Ni Hon Saku. Tokyo: 3A Corporation.

Tsujimura, N. 2014. An Introduction to Japanese Language. West Sussex: BlackwellPublisher. 